\title{
The frequency of the dyadic influence tactics according to communication media
}

\author{
Vicenc Fernandez, Pep Simo, Mihaela Enache, Jose M. Sallan \\ Department of Management, Universitat Politècnica de Catalunya, Terrassa, Spain \\ vicenc.fernandez@upc.edu; \\ One of the most important determinants of managerial effectiveness in achieving \\ organizational objectives is the success in influencing subordinates, lateral peers and \\ supervisors through influence tactics. However, little attention has been paid to the use of a \\ communication media in the context of influence tactics. Our objective is to study the \\ frequency of these dyadic influence tactics on diverse communication media. The study \\ involves a questionnaire-based survey conducted on Spanish post-graduate students who had \\ been working in medium sized or large companies during the last two years or more. The \\ results suggest that the richness of the medium explains most similarities and differences in \\ the frequency of influence tactics for different communication media. Furthermore, in the \\ study of hard influence tactics in communication media with similar richness, it is necessary \\ to introduce social aspects and the level of surveillance in order to explain it fully. This study \\ helps managers to understand the relationships between influence tactics and the use of \\ communication media-in order to improve their communication effectiveness.
}

Keywords: communication media; dyadic influence tactics; media richness theory; organizational communication

\section{Introduction}

One of the most important determinants of managerial effectiveness in achieving personal and organizational objectives is the skill of influencing subordinates, lateral peers and supervisors (Yukl 1989). In this context, it is interesting to highlight the dyadic influence tactics that are described as the set of strategies that an individual uses in order to alter the attitudes, cognitions and behaviours of other individuals (Yukl and Falbe 1990). Research on these influence strategies has been centred on the identification and definition of dyadic influence tactics, as well the study of their frequency of use depending on the influence objectives and targets (Kipnis et al. 1980, Yukl et al. 2005). However, little attention has been paid to communication media used by influence seekers to pursue their objectives. In this line, Barry and Bateman (1992) and Barry and Fulmer (2004) suggested that the use of communication media could be closely related to 
communication intentionality. Based on these suggestions, the objective of the present research is twofold: (a) first, to test whether managers' use frequency of an influence strategy is related to the selected communication media, and (b) second, to identify those communication theories, which explain the existing relationships between the use of the dyadic influence tactics and communication media. In order to achieve these objectives,

data were gathered and examined through a field survey study, to assess the frequency of each dyadic influence tactic according to three communication media. Finally, based on the findings and drawing on the knowledge gleaned from a review of the existing literature on communication media selection, this paper suggests some conclusions and practical implications for improving managerial effectiveness, as well as some proposals for future research.

\section{Dyadic influence tactics in organizations}

Social influences have been mainly analyzed from two perspectives: micro and macro. At the micro level, existing studies have examined how people manage others’ opinions and activities with the aim of achieving certain objectives. This research focuses on the context of social influences, and more specifically, on the dyadic social influences that are defined as the process through which an individual (agent) deliberately selects and presents verbal and/or symbolic actions directed at another individual (target) with the expectation of those actions that will bring about a desired change in the cognitions and/or behaviours of the target that would not have otherwise occurred (Barry and Watson 1996). 


\subsection{Social influence tactics}

A review of the literature reveals the existence of a significant number of models and frameworks that theorize on social influence processes (Cobb 1986, Dillard 1990, Kipnis et al. 1980, Raven 1992). Each model or framework suggests various antecedents, characteristics and processes of social influence mechanisms, such as: process objectives, organizational social norms and the agent's learning process. Because of this, a large variety of taxonomies of social influence has been developed in the organizational context. On one hand, the selection and measurement of influence tactics differ substantially between different studies, as does the criteria used to evaluate tactics (Yukl and Tracey 1992). On the other hand, the methodological differences between the studies are also substantial, with the tactics and their outcomes measured in different ways from one study to the next (Falbe and Yukl 1992). According to Kellermann and Cole (1994), the existing typologies have created taxonomic disorder and confusion. For instance, the labels used for making reference to influence tactics vary in a myriad of theoretical ways: influence strategies (Hirokawa and Miyahara 1986), influence tactics (Kipnis et al. 1980), influence methods (Porter et al. 1981), and influence forms (Vecchio and Sussmann 1991). According to the literature, these taxonomies can be classified into behaviours, categories and dimensions, which reflect the structure of this chaotic classification system.

\subsection{Classification of dyadic influence tactics}

Kipnis et al. (1980) developed one of the first questionnaires to evaluate influence tactics - the Profiles of Organizational Influence Strategies (POIS), which was based on a classification system encompassing eight tactics of influence (“Ingratiation”, “Rationality”, “Assertiveness”, “Sanctions”, “Exchange”, “Upward appeal”, “Blocking”, 
and “Coalitions”). Later, Kipnis and Schmidt (1985) suggested that dyadic influence tactics can be grouped into three categories: hard tactics, soft tactics, and rational persuasion tactics.

Subsequently, Yukl and Falbe (1990) introduced two new influence tactics, namely "inspirational appeals" and "consultation" to the Kipnis et al. (1980) classification, as well as removing the influence tactics "sanctions" and "blocking" because of conceptual bias. From this new classification, the authors developed the popular 8-scale Influence Behaviour Questionnaire (IBQ) for evaluating dyadic influence tactics. Drawing on previous research, Falbe and Yukl (1992) refined the classification of dyadic influence tactics and developed an improved version of the Influence Behaviour Questionnaire (IBQ), by introducing a new proactive influence tactic, called "personal appeal". Finally and based on empirical studies, Yukl et al. (2005) evaluated the construct validity of "collaboration" and "apprising" as proactive influence tactics. The findings of their analysis indicated that "collaboration" and "apprising" were distinct from the nine proactive tactics previously proposed in the IBQ. Although there are some similarities between the "collaboration" and "exchange” tactics, the research showed significant differences regarding their antecedents and consequences. The same conclusions were obtained for "rational persuasion” and "apprising” tactics. In that case, significant differences were observed in their mediating processes. A complete list of dyadic influence tactics and their definitions are illustrated in the Table 1.

Table 1. Definitions of Influence Tactics based on Fable and Yukl (1992) and Yukl, Chavez and Seiefert (2005)

Scale

Pressure Tactics

\section{Definition}

The person uses demands, threats, or intimidation to convince you to comply with a request or to support a 


\begin{tabular}{|c|c|}
\hline & proposal \\
\hline $\begin{array}{l}\text { Legitimating or Upward } \\
\text { Appeals }\end{array}$ & $\begin{array}{l}\text { The person seeks to establish the legitimacy of a request by } \\
\text { claiming the authority or right to make it or verifying that it } \\
\text { is consistent with organizational, policies, rules, practices, or } \\
\text { traditions. }\end{array}$ \\
\hline Exchange tactics & $\begin{array}{l}\text { The person makes an explicit or implicit promise that you } \\
\text { will receive rewards or tangible benefits if you comply with } \\
\text { a request or support a proposal, or reminds you of a prior } \\
\text { favour to be reciprocated. }\end{array}$ \\
\hline Collaboration tactics & $\begin{array}{l}\text { The person offers to make it easier or less costly for you to } \\
\text { carry out the request. Collaboration includes offering to } \\
\text { provide relevant resources, offering to provide assistance in } \\
\text { carrying out a requested task, and offering to help } \\
\text { circumvent obstacles. }\end{array}$ \\
\hline Coalition tactics & $\begin{array}{l}\text { The person seeks the aid of others to persuade you to do } \\
\text { something or uses the support of others as an argument for } \\
\text { you to agree also }\end{array}$ \\
\hline Ingratiating tactics & $\begin{array}{l}\text { The person seeks to get you in a good mood or to think } \\
\text { favourable of him or her before asking you to do something }\end{array}$ \\
\hline Rational persuasion & $\begin{array}{l}\text { The person uses logical arguments and factual evidence to } \\
\text { persuade you that a proposal or request is viable and likely to } \\
\text { result in the attainment of task objectives }\end{array}$ \\
\hline Apprising tactics & $\begin{array}{l}\text { The person explains why a request or proposal is likely to } \\
\text { benefit you as an individual. Possible benefits include a } \\
\text { larger pay increase, faster career advancement, and } \\
\text { opportunities to learn new skills }\end{array}$ \\
\hline Inspirational appeals & $\begin{array}{l}\text { The person makes a request or proposal that arouses } \\
\text { enthusiasm by appealing to your values, ideals, and } \\
\text { aspirations or by increasing your confidence that you can do } \\
\text { it. }\end{array}$ \\
\hline Consultation tactics & $\begin{array}{l}\text { The person seeks your participation in planning a strategy, } \\
\text { activity, or change for which support and assistance are } \\
\text { desired, or the person is willing to modify a proposal to deal } \\
\text { with your concerns and suggestions }\end{array}$ \\
\hline Personal appeal & $\begin{array}{l}\text { The person appeals to your feelings of loyalty and friendship } \\
\text { toward him or her before asking you to do something. }\end{array}$ \\
\hline
\end{tabular}

\subsection{Communication media and influence tactics}

As outlined earlier, significant research has been conducted on dyadic influence tactics in organizations; however, only minimal attention has been paid to the role of the 
communication media through which influence seekers pursue their social objectives. For instance, Bordia (1997) and Barry and Fulmer (2004) argued that there is still limited understanding of the effects of the communication media upon these interpersonal influences. Barry and Batteman (1992) suggested that the use of the communication media and of influence tactics are not independent. Later, Barry and Fulmer (2004) argued that people could adapt available communication media into dyadic influence tactics, and that the use of a communication medium may depend upon the strategy chosen by the supervisor to influence an employee’s behaviour. In spite of these suggestions, no empirical research has been found that checked or analyzed these relationships in the literature. As shown in the references, this relationship has been hypothesized by the authors and can be summarized by hypothesis 1 .

H1: The use of dyadic influence tactics is related to the communication media selected.

As a consequence of this hypothesis, a new question arises: what kinds of relationships exist between the use of communication media and dyadic influence tactics? The current literature on the selection and use of communication media could help answer this question.

\subsection{Theories about the selection and use of communication media}

The literature on communication media reflects a myriad of interrelated theories on the causes that determine the selection of a communication media and its use : media richness (Daft and Lengel 1984), social influence (Schmitz and Fulk 1991), media symbolism (Trevino et al. 1987), situational factors (Short et al. 1976), critical mass (Markus 1987), and communication genres (Yates and Orlikowski 1992). These theories 
on the preference of communication media use can be represented on a continuum (Vishwanath 2006), placing at one extreme rational decision making theories and at the other the theories that emphasize social influences. Despite the existence of so many theories, media richness theory and social influence theory are the most predominant to describe how and why people choose a particular media in order to communicate with other people (Te'eni et al. 2001). Media richness theory has focused on the bandwidth of a media in determining its capability to convey the meanings or intentions of the communication partners, while social influence theory has focused on the social aspects as determining factors. These theories constitute a starting point in identifying the relationships between dyadic influence tactics and communication media.

Media richness theory, the most popular theory of media use, suggests that communication media are characterized by their level of information richness, where the term "richness" refers to the potential information a medium can transmit. According to this theory, a rich medium enables efficient feedback, supports multiple cues through multiple channels of communication (e.g., verbal and nonverbal communication), facilitates the use of language variety (e.g., numbers and pictures), and allows for a high degree of personalized input. Based on these characteristics, face-to-face is considered the richest medium, while the telephone and electronic mail are assessed only as rich media. Personal and physical documents are considered moderately rich media, while non-personal documents and unaddressed channels are contemplated as low rich media. From this perspective, the following hypothesis is proposed:

H2: The use of dyadic influence tactics is different between communication media with different levels of richness. 
From a different perspective, the social influence theory of communication media is based on the premises of Social Information Processing Theory (Salancik and Pfeffer 1978), Social Learning Theory (Bandura 1986), and Symbolic Interactionism (Mead 1934). This theory states that the perceptions of a communication media are partly built through the individual's interaction with the media and the larger social structure within which the individual is embedded (Vishwanath 2006). This suggests that the selection of a communication medium is merely subjective and depends mainly on external factors (Fulk 1993, Weick 1990). According to this theory, managers should consider the consequences of their communication strategies, as the use of hard tactics could contradict the culture and the values of the organization and even exert an influence on the social environment of the organization. Therefore, it is logical to consider that managers who decide to use hard tactics contemplate more features regarding the use of the communication media than the features proposed by media richness theory. This reasoning suggests the following hypothesis:

H3: The use of dyadic influence tactics is different between communication media with a similar level of richness according to the kind of tactic (hard or soft tactics).

\section{Method}

\subsection{Sample}

A questionnaire was distributed anonymously to a sample of 92 respondents (29.35\% women and $70.65 \%$ men), with an average age of 27.83 . All respondents who volunteered to participate in this study were post-graduate students from business courses, who had been working in medium sized or large companies during the last two years or more. The sample included respondents from different industries: $14.13 \%$ 
metallurgic companies, 13.04\% automotive companies, 11.96\% telecommunications and industrial engineering, $11.96 \%$ chemical companies, 9.78\% power supplies, 3.26\% banks, 3.26\% construction companies, $2.17 \%$ logistic companies, and 30.43\% other industries. Although only $43.48 \%$ of the respondents had some managerial responsibilities, this was not considered a necessary condition as a target-directed questionnaire was used rather than an agent-directed questionnaire, as Yukl, Seifert and Chavez (2008) suggest. Respondents were assured that their individual responses would remain confidential and that only a composite summary based on their responses would be used. On receiving the questionnaires, all those situations in which the influence strategy was applicable to a single communication medium (e.g. people who always communicated face-to-face with their supervisors because all employees worked at the same place) and those which were not applicable to the particular situation of the respondent were eliminated. The respondents were asked to select one supervisor with whom they communicated on a regular basis, through different media, and with whom they hade worked for at least 6 months. Respondents were asked to keep that person in mind as they responded to the survey items.

\subsection{Instrument}

In order to evaluate the influence tactics, a target-directed questionnaire was adapted, based on the 1992 version of the Influence Behaviour Questionnaire (IBQ) developed by Falbe and Yukl (1992) and from subsequent contributions by Yukl et al. (2005), who included two new influence tactics. This questionnaire evaluated the frequency of the influence tactics illustrated in Table 1 in three communication media (face-to-face, telephone and electronic mail). The questionnaire also included demographic items 
(gender, age and studies level), items about respondents' jobs inside the organization and the industry, as well as the size of the employer organization. Because the general language of the target population was Spanish, the questionnaire had to be translated into this language. To ensure the accuracy of the translation, we followed a back-translation procedure (Nunnally and Bernstein 1994). Also, three cognitive interviews were conducted in order to ensure an accurate interpretation of the questionnaire items, as this technique allows for an understanding about how respondents perceive and interpret questions, and to identify potential problems that may arise in prospective survey questionnaires (Drennan 2003). The cognitive interviews enabled an interpretation of which items are beyond the theoretical framework of the constructs to be analyzed (Collins 2003, Jobe and Mingay 1989). By means of verbal probing and thinking aloud (Drennan 2003, Williamson et al. 2000) participants were asked to verbalize their interpretation of items and to paraphrase and/or comment on the wording of items in an effort to identify ambiguous or poorly worded questions.

Each tactic scale had three items, and each item had five anchored response choices indicating how often the supervisor, who respondents had selected, used the tactic. Hence, the final questionnaire had 99 items (11 scales x 3 items/scale x 3 communication media). The order of items per scale was randomized to avoid bias. Two sample items for a pressure tactic are the following: 'My supervisor insists in a assertive way that you must carry out a request' and 'My supervisor repeatedly checks and reminds you that his/her task has not been carried out yet'. In the case of legitimating persuasion the sample items are: 'My supervisor says that his/her request is consistent with organizational rules, policies, tradition and precedents' and 'My supervisor says that 
his/her request is legitimate according to the proper authorities'. Another two items, which were used to assess the personal appeal, are the following: 'My supervisor asks me to help him/her accomplish a task as a personal favor' and 'My supervisor says that he/she would really appreciate my help’. Finally, two items for rational persuasion are: 'My supervisor explains in detail the reasons for a request in a clear, logic and convincing way' and 'My supervisor justifies his/her request using facts when necessary'. Response choices in the last version of the questionnaire were as follows: (1) Never uses this influence tactic though this communication media, (2) Seldom uses this influence tactic though this communication media; (3) Occasionally uses this influence tactic though this communication media; (4) Quite often uses this influence tactic though this communication media; and (5) Very often uses this influence tactic though this communication media.

Due to the fact that the internal consistency of a translated survey to another language is not guaranteed (Morales et al. 2003), the authors analyzed it thoroughly. The scores on all eleven dyadic influence tactics in the three communication media (face-toface, telephone and electronic mail) showed a satisfactory level of internal consistency, as evidenced by reasonably high values of Cronbach’s coefficient alpha (Cronbach 1951)of between 0.87 and 0.98 .

\section{Results}

All statistical analyses were done with SPSS 17.0. To test the hypotheses, the authors selected the option "repeated measures" of a general linear model procedure of SPSS software, which allows for adjusting models of one-factor ANOVA and models of multifactors ANOVA with repeated measures on all, or only some, factors. In this case, the 
intra-subject factor was defined as the communication medium, and three variables (faceto-face, telephone, and electronic mail) as the three levels for this factor.

Table 2 shows the mean frequency and standard deviations of all eleven dyadic influence tactics for each communication media. These results show that the mean frequency of each dyadic influence tactic is always higher in face-to-face communications than in telephone and electronic mail. However, the results are not so extreme when comparing the telephone and electronic mail. On one hand, the mean frequency of some dyadic influence tactics (e.g. Exchange tactics and Inspirational appeal) are higher in telephone communication than in electronic mail, and on the other hand, these means in the rest of dyadic influence tactics (e.g. Legitimating appeal and Apprising tactics) are lower in telephone communication than in electronic mail. These preliminary results suggest some similarities between the telephone and electronic mail and some important differences between face-to-face communication and the other two. Various respondents specified that some kinds of dyadic influence tactics were not applicable to his/her context (e.g Personal appeal tactics were less frequent than Ingratiating tactics). For this reason, the Table 2 and 3 shows different values of $\mathrm{N}$. According to these results the dyadic influence tactics that are most common among the three communication media are "Ingratiating tactics" ( $\mathrm{N}=84)$, and "Apprising tactics” ( $\mathrm{N}=81$ ); while the least common among the studied communication media are "Collaboration tactics" $(\mathrm{N}=48)$ and "Personal appeal” $(\mathrm{N}=51)$. In most cases, these results are directly related to the frequency of the dyadic influence tactics for each communication media. 
Moreover, the last column of Table 2 also shows the results of a one-way analysis of variance with repeated measures (ANOVA-RM) of the three communication media for each dyadic influence tactic. The results of the variance analysis reveal that the frequency of a dyadic influence tactic is not the same, in principle, for each communication medium (with a $\mathrm{p}<0.001$ ). According to this F-test, hypothesis 1 is therefore supported for each dyadic influence tactic.

Table 2. Frequency Mean and Standard Deviations (between brackets) of Dyadic Influence Tactics for each Communication Media and Analysis of Variance Results

\begin{tabular}{|c|c|c|c|c|}
\hline \multirow[b]{2}{*}{ Influence Tactic } & \multicolumn{3}{|c|}{ Factor: Communication media } & \multirow[b]{2}{*}{ F-test } \\
\hline & Face-to-Face & Telephone & $\begin{array}{c}\text { Electronic } \\
\text { Mail }\end{array}$ & \\
\hline $\begin{array}{l}\text { Pressure Tactics } \\
(\mathrm{N}=73)\end{array}$ & $\begin{array}{c}3.27 \\
(1.29)\end{array}$ & $\begin{array}{c}2.19 \\
(1.17)\end{array}$ & $\begin{array}{c}2.51 \\
(1.24)\end{array}$ & $25.667 *$ \\
\hline $\begin{array}{l}\text { Legitimating or } \\
\text { Upward Appeals } \\
(\mathrm{N}=74)\end{array}$ & $\begin{array}{c}3.49 \\
(1.14)\end{array}$ & $\begin{array}{c}1.88 \\
(1.02)\end{array}$ & $\begin{array}{c}2.41 \\
(1.41)\end{array}$ & $80.380 *$ \\
\hline $\begin{array}{l}\text { Exchange tactics } \\
(\mathrm{N}=54)\end{array}$ & $\begin{array}{c}3.15 \\
(1.17)\end{array}$ & $\begin{array}{c}2.17 \\
(1.21)\end{array}$ & $\begin{array}{c}2.07 \\
(0.99)\end{array}$ & $26.638 *$ \\
\hline $\begin{array}{l}\text { Collaboration tactics } \\
(\mathrm{N}=48)\end{array}$ & $\begin{array}{c}3.08 \\
(1.11)\end{array}$ & $\begin{array}{c}2.04 \\
(1.18)\end{array}$ & $\begin{array}{c}2.08 \\
(1.18)\end{array}$ & $13.309 *$ \\
\hline $\begin{array}{l}\text { Coalition tactics } \\
(\mathrm{N}=78)\end{array}$ & $\begin{array}{c}3.24 \\
(1.18)\end{array}$ & $\begin{array}{c}1.95 \\
(1.17)\end{array}$ & $\begin{array}{c}2.05 \\
(1.20)\end{array}$ & $62.982 *$ \\
\hline $\begin{array}{l}\text { Ingratiating tactics } \\
(\mathrm{N}=84)\end{array}$ & $\begin{array}{c}4.12 \\
(0.87)\end{array}$ & $\begin{array}{c}2.67 \\
(1.31)\end{array}$ & $\begin{array}{c}2.68 \\
(1.31)\end{array}$ & $94.984 *$ \\
\hline $\begin{array}{l}\text { Rational persuasion } \\
(\mathrm{N}=76)\end{array}$ & $\begin{array}{c}3.59 \\
(1.07)\end{array}$ & $\begin{array}{c}2.58 \\
(1.71)\end{array}$ & $\begin{array}{c}2.41 \\
(1.31)\end{array}$ & 46.888* \\
\hline $\begin{array}{l}\text { Apprising tactics } \\
(\mathrm{N}=81)\end{array}$ & $\begin{array}{c}3.91 \\
(0.95)\end{array}$ & $\begin{array}{c}2.56 \\
(1.42)\end{array}$ & $\begin{array}{c}2.90 \\
(1.46)\end{array}$ & $54.865 *$ \\
\hline $\begin{array}{l}\text { Inspiratonal appeals } \\
(\mathrm{N}=55)\end{array}$ & $\begin{array}{c}3.31 \\
(1.10)\end{array}$ & $\begin{array}{c}2.31 \\
(1.36)\end{array}$ & $\begin{array}{c}1.87 \\
(1.06)\end{array}$ & 47.633* \\
\hline $\begin{array}{l}\text { Consultation tactics } \\
(\mathrm{N}=76)\end{array}$ & $\begin{array}{c}3.53 \\
(1.08)\end{array}$ & $\begin{array}{c}2.29 \\
(1.26)\end{array}$ & $\begin{array}{c}2.36 \\
(1.25)\end{array}$ & $54.341^{*}$ \\
\hline $\begin{array}{l}\text { Personal appeal } \\
(\mathrm{N}=52)\end{array}$ & $\begin{array}{c}3.35 \\
(1.17)\end{array}$ & $\begin{array}{c}1.75 \\
(1.06)\end{array}$ & $\begin{array}{c}1.60 \\
(1.00)\end{array}$ & $54.499 *$ \\
\hline
\end{tabular}


$* p<0.001$

As a consequence of the variance analysis results, the authors decided to repeat the analysis of whether the communication media affects the frequency of each dyadic influence tactic but by considering only two communication media instead of three at the same time. As the research considers three communication media, the authors carried out three analyses: one with communication media face-to-face and telephone, a second between the telephone and e-mail, and a third with face-to-face and e-mail. The goal was to analyze if there are differences between behaviour when a person is using one communication medium or another. In order to carry out these analyses, the authors used the Wilks' lambda statistical test, which is used in multivariate analysis of variance (MANOVA) to test whether there are differences between the means of identified groups of subjects with a combination of dependent variables. The scores of Wilks' lambda fluctuates between 0 and 1 , where a value close to zero means that the factor has a high explanatory power, and values close to one have the opposite effect. The results on Wilks's lambda tests for the three combinations of communication media are shown in Table 3.

Table 3. Results of Wilks's Lambda Test for each Combination of Communication Media

\begin{tabular}{lccc}
\hline \multirow{2}{*}{ Influence Tactic } & \multicolumn{2}{c}{ Wilks's lambda: Communication media } \\
\cline { 2 - 4 } & $\begin{array}{c}\text { Face-to-Face } \\
\text { Telephone }\end{array}$ & $\begin{array}{c}\text { Telephone } \\
\text { E-Mail }\end{array}$ & $\begin{array}{c}\text { Face-to-Face } \\
\text { E-Mail }\end{array}$ \\
\hline $\begin{array}{l}\text { Pressure Tactics } \\
\text { (N=73) }\end{array}$ & $0.61^{*}$ & $0.96+$ & $0.76^{*}$ \\
$\begin{array}{l}\text { Legitimating or Upward } \\
\text { Appeals } \\
\text { (N=74) }\end{array}$ & $0.32^{*}$ & $0.92+$ & $0.67^{*}$ \\
Exchange tactics & $0.584^{*}$ & 0.99 & $0.56^{*}$
\end{tabular}


$(\mathrm{N}=54)$

Collaboration tactics

$(\mathrm{N}=48)$

$\begin{array}{lll}0.67^{*} & 1.00 & 0.68^{*}\end{array}$

Coalition tactics

$(\mathrm{N}=78)$

$0.424^{*}$

0.99

$0.54 *$

Ingratiating tactics

$(\mathrm{N}=84)$

$0.41 *$

1.00

$0.43 *$

Rational persuasion

$(\mathrm{N}=76)$

$0.55^{*}$

0.99

$0.50 *$

Apprising tactics

$(\mathrm{N}=81)$

$0.51^{*}$

0.971

0.59*

Inspirational appeals

$(\mathrm{N}=55)$

$0.55^{*}$

$0.90+$

$0.40 *$

Consultation tactics

$(\mathrm{N}=76)$

$\begin{array}{lll}0.50 * & 1.00 & 0.49 *\end{array}$

Personal appeal

$(\mathrm{N}=52)$

$0.38 *$

0.98

$0.36 *$

${ }^{*} p<0.001 ;+\mathrm{p}<0.1$

In the cases where the authors analyzed the differences between behaviour in face-to-face and telephone communications, and face-to-face and electronic mail, Table 3 shows that their explained variance ranges between 0.32 and 0.76 ; however, Wilks's Lambda tests for each dyadic influence tactic show that the use of face-to-face or any other two communication media (see first and third column in the Table 3) has a medium-high explanatory power and are also significantly different. In other words, the use of any dyadic influence tactic is not the same for these communication media with a $\mathrm{p}<0.001$. The results of Wilks's Lambda tests for each influence tactic in these two cases are very similar except for the "Legitimating or Upward Appeal” where the Wilks's Lambda in the combination face-to-face and telephone are much lower (0.32) than in face-to-face and electronic mail (0.67), thus the differences are better explained in the first situation than in the second. On the other hand, the results of the Wilks's Lambda 
test between the telephone and electronic mail communications are different and interesting.

The Wilks's Lambda scores (see second column of Table 3) are very high for all dyadic influence tactics, which means that the similarities and differences in their frequency are not sufficiently explained by the use of these two communication media; therefore, the differences between these media have a low explanatory power. The results between the Wilks Lamda test which analyzes the differences between face-to-face (high richness) and telephone or electronic mail (moderate richness) communication media, and the test between telephone and electronic mail (moderate richness) communication media show that hypothesis 2 is supported.

However, these results also show that there are three tactics where frequencies are significantly different, but low, in the test between telephone and electronic mail communication media: "Pressure tactics”, “Legitimating or Upward Appeals”, and “Inspirational Appeal”. Their Wilk’s Lamda scores are 0.96, 0.92, and 0.90 respectively. Kipnis and Schmidt (1985) identified two commonly used hard tactics: "Pressure tactics" and "Legitimating or Upward Appeals", which are two of the three tactics previously mentioned. Therefore, these results suggest that the use of hard tactics is different when the analyzed communication media have a similar richness level; while that the use of soft tactics (“Exchange tactics”, “Collaboration tactics”, “Coalition tactics”, "Ingratiating tactics”, “Apprising tactics”, “Consultation tactics”, "Personal appeal”, with the exception of "Inspirational Appeal”), and “Rational persuasion” tactics depends on the richness level of the communication media. At the same line, Cable and Judge (2003) have already suggested that the behaviours and the attitudes of managers with hard 
strategies could be very different from other influence tactics. Therefore, these results support, partially, hypothesis 3.

\section{Discussion of the Results}

The previous results agree with the suggestions and proposals of Barry and Batteman (1992) and Barry and Fulmer (2004) that a supervisor could adapt the dyadic influence tactics according to the available communication media in order to influence the employee's behaviour. The frequency of dyadic influence tactics, according to these results, are always different between media with different levels of richness, such as faceto-face with telephone or electronic mail. In cases where the level of richness is similar (e.g. telephone and electronic mail), media richness theory explains most of the results according to the type of dyadic influence strategy, with the exception of hard tactics and “Inspirational appeal”. The authors have not identified any theory on communication, which could explain why the "Inspirational appeal" tactic does not behave in the same way as the rest of the soft tactics. Therefore, subsequent research on that theory could expand our understanding of these results, particularly with results related to this dyadic influence tactic.

An alternative explanation about the results regarding hard tactics between communication media with similar richness could come from the surveillance level of the media. Lewicki et al. (2003) suggested that the surveillance level, reflecting the degree to which the canal allows surveillance, could be another key variable in the selection of a communication medium. As explained before, the use of hard tactics can be considered as a negative practice or custom in many organizations. In our study, the level of surveillance explains why the use of hard tactics by telephone is higher than the use of 
the same tactics by electronic mail. The first has a low level of surveillance, as it is difficult to prove the use of a hard tactic by telephone; so managers who want to use this kind of tactics will feel safer in case of reprisals. On the other hand, electronic mail communication has a high level of surveillance, due to the fact that the messages are stored in the server and could be used against the author of the message. In that case, managers decide not to use this kind of tactic by electronic mail as often.

As the data of this research has been gathered from a Spanish population, the authors believe that it is interesting to compare the results about the use of dyadic influence tactics with previous research from the USA. Table 4 shows the influence tactics in order, according to their frequency for USA and Spanish populations. These results suggest that the most frequent tactic is "Rational persuasion for USA population"; while, the least common is “Exchange tactics” (Yukl et al. 2008). These results are very similar to those obtained for the Spanish population. As Table 4 shows, the differences in the order of dyadic influence tactics between the two populations differ only in two positions in the majority of cases. There are only three cases where the order of influence tactics is very different: “Collaboration tactics”, “Apprising tactics” and "Personal appeal”. On one hand, the first tactic is much less common in Spain than in the USA. On the other hand, the other two influence tactics are more common in Spanish companies than in American ones. From a general point of view, the authors believe that there are few differences between the two populations; therefore the results of this research could be extrapolated to other countries taking into account these small differences.

Table 4. Differences between USA and Spanish samples related too dyadic influence tactics

\begin{tabular}{llll}
\hline Influence Tactic & USA & Spain & Difference $(\Delta)$ \\
\hline
\end{tabular}




\begin{tabular}{lccc}
\hline Rational persuasion & $1^{\text {st }}$ & $3^{\text {rd }}$ & +2 \\
Consultation tactics & $2^{\text {nd }}$ & $4^{\text {th }}$ & +2 \\
Ingratiating tactics & $3^{\text {rd }}$ & $1^{\text {st }}$ & -2 \\
Collaboration tactics & $4^{\text {th }}$ & $11^{\text {th }}$ & +7 \\
Inspirational appeals & $5^{\text {th }}$ & $7^{\text {th }}$ & +2 \\
Legitimating appeals & $6^{\text {th }}$ & $5^{\text {th }}$ & -1 \\
Apprising tactics & $7^{\text {th }}$ & $2^{\text {nd }}$ & -5 \\
Pressure tactics & $8^{\text {th }}$ & $8^{\text {th }}$ & 0 \\
Coalition tactics & $9^{\text {th }}$ & $9^{\text {th }}$ & 0 \\
Personal appeal & $10^{\text {th }}$ & $6^{\text {th }}$ & -4 \\
Exchange tactics & $11^{\text {th }}$ & $10^{\text {th }}$ & -1 \\
\hline
\end{tabular}

\subsection{Managerial implications}

Our research findings have some managerial implications to improve organizational effectiveness. After checking the existence of relationships between the influence tactics and the choice of communication media, the authors found that the understanding of these relationships by managers would help them to communicate with their subordinates and co-workers in a more efficient way. Managers should consider and understand the factors that influence the choice of communication media and influence tactics, such as the level of richness (feedback, multiple cues, multiple channels, language variety, and degree of personal persuasion) and the level of surveillance, in order to achieve personal and, specially, organizational objectives.

\subsection{Limitations and suggestions for future research}

This study analyzes the existence of relationships between dyadic influence tactics and communication media by analyzing three media: face-to-face, telephone and electronic mail. Our main limitation is that the empirical study only analyzes the most common communication media in organizations, without considering other less common media, such as Instant Messenger or videoconferencing. However, the authors consider that the study of these other communication media would not change the results of our analysis, 
as the majority of communications inside an organization are made by face-to-face, telephone and electronic mail. Another consideration refers to the level of richness of the communication media analyzed. The literature asserts that face-to-face communication has a very high level of richness, while telephone and electronic mail are communication media with just high or moderated richness. The study of other media with low moderate and low richness could explain in more detail how the features of richness (feedback, multiple cues, multiple channels, language variety, and degree of personalness) of a communication medium affect the relationships to the influence tactics. Finally, the sample of this empirical study comes from Spanish respondents and from different levels of management; therefore it would be interesting to check if there is any difference in the frequency of the tactics across cultures and different levels of management.

Another limitation is the population of the sample. On one hand, all respondents were post-graduate students, therefore the sample is not a complete representation of the Spanish employees, but a subset of them characterized by having university degrees and a short work experience (the average age was 27.83). It is necessary to take into account this fact in the generalization of these results to the rest of the Spanish population. On the other hand, only some of them had managerial responsibilities. Although the authors have followed the suggestions of Yukl et al. (2008) on this issue, it would be interesting to check the differences between the supervisors and subordinates' perspectives about the use of dyadic influence tactics. To achieve this goal, an agent-directed questionnaire, equivalent to the used one in this research, could be developed and distributed among supervisors. 
The research findings suggest the need to keep investigating the reasons why managers make these decisions, as well as the efficiency of the combinations between influence tactics and communication media, in order to improve the results of managers' communication. In addition, the nature of causality between the choice of dyadic influence tactics and communication media is another interesting aspect for future research. Therefore, these findings suggest further work and research drawing on the theories regarding the causes that determine the choice and use of a communication media. Furthermore, the research has showed that media richness theory allows us to explain the results of the empirical study, but also raises the question whether another theory (e.g. critical mass) could explain other differences about the choice of influence tactics and communication media The authors believe that further work on this issue from two different perspectives or theoretical fields can help us to understand how to improve managerial communication.

\section{Conclusions}

The abilities and skills of influencing subordinates, lateral peers and supervisors are essential in achieving managerial effectiveness. To this end, managers have had a wide range of dyadic influence tactics from which to choose, and the spread of new communication media has diffused the use and the efficiency of these influence tactics. The literature shows that the selection of an influence tactic depends on factors related to personal and organizational goals; however, recent research in the field suggests that the communication media could also influence these choices. Therefore, the objective of this research was to test whether the frequency of a managers' choice of a dyadic influence tactic is related to the chosen communication medium, and to find a justification for the 
relationship between the use of dyadic influence tactics and the communication media, based on the current theories about the choice of communication media. These results could improve managerial communication in organizations.

The findings of this study are the following: (1) according to global variance analysis, the frequency of dyadic influence tactics is not the same for all communication media; these results confirm the proposals by other researchers (e.g. Barry and Fulmer, 2004) regarding the importance of managers and employees’ perceptions of the communication media on their dyadic influence strategies. (2) The differences in the frequency of the dyadic influence tactics for each communication medium depend mainly on their level of richness. The results show similar behaviour between the telephone and the electronic mail communications, where the level of richness is very similar; however, different results were found between face-to-face communications and the rest (telephone and electronic mail, independently), where the level of richness is different. Although media richness theory explains a high percentage of the similarities and differences in the frequency an influence tactic for every communication medium, there are also other factors related to media that can influence this.

In spite of the fact that the results on the frequency of influence tactics being very similar for communication media with the same level of richness, the authors have observed small differences between hard tactics and other tactics. This fact can be explained by the social context and/or the level of surveillance of the medium. According to Barry and Fulmer (2004), the medium's level of surveillance could be one of the most important factors in the choice of communication media. Our results are consistent with this assertion. Finally, this study is the first to empirically find that the frequency of 
dyadic influence tactics is related to communication media in terms of media selection theories.

\section{References}

Bandura, A., 1986. The explanatory and predictive scope of self-efficacy theory. Journal of Social and Clinical Psychology, 4(3), 359-373.

Barry, B. and Bateman, T., 1992. Perceptions of Influence in Managerial Dyads - the Role of Hierarchy, Media, and Tactics. Human Relations, 45(6), 555-574.

Barry, B. and Fulmer, I.S., 2004. The medium and the message: The adaptive use of communication media in dyadic influence. Academy of Management Review, 29(2), 272-292.

Bordia, P., 1997. Face-to-face versus computer-mediated communication: A synthesis of the experimental literature. Journal of Business Communication, 34, 99-120.

Cable, D.M. and Judge, T.A., 2003. Managers' upward influence tactic strategies: the role of manager personality and supervisor leadership style. Journal of Organizational Behavior, 24(2), 197-214.

Cobb, A., 1986. Informal influence in the formal organization - Psychological and situational correlates. Group \& Organization Studies, 11(3), 229-253.

Collins, D., 2003. Pretesting survey instruments: An overview of cognitive methods. Quality of Life Research, 12(3), 229-238.

Cronbach, L., 1951. Coefficient alpha and the internal structure of tests. Psychometrika, 16(3), 297-334.

Daft, R. and Lengel, R., 1984. Information richness: A new approach to managerial behavior and organizaton design. Research in Organizational Behavior, 6, 191233.

Drennan, J., 2003. Cognitive interviewing: verbal data in the design and pretesting of questionnaires. Journal of Advanced Nursing, 42(1), 57-63.

Falbe, C. and Yukl, G., 1992. Consequences for managers of using single influence tactics and combinations of tactics. Academy of Management Journal, 35(3), 638652.

Fulk, J., 1993. Social construction of communication technology. Academy of Management Journal, 36(5), 921-950.

Hirokawa, R. and Miyahara, A., 1986. A comparison of influence strategies utilized by managers in American and Japanese organizations. Communication Quarterly, 34, 250-265.

Jobe, J.B. and Mingay, D.J., 1989. Cognitive research improves questionnaires. American Journal of Public Health, 79(8), 1053-1055.

Kellermann, K. and Cole, T., 1994. Classifying compliance gaining messages Taxonomic disorder and strategic confusion. Communication Theory, 4(1), 3-60.

Kipnis, D., Schmidt, S. and Wilkinson, I., 1980. Intraorganizational Influence Tactics Explorations in Getting Ones Way. Journal of Applied Psychology, 65(4), 440452. 
Kipnis, D. and Schmidt, S., 1985. The language of persuasion. Psychology Today, 19(4), 40-\&.

Lewicki, R., Barry, B., Saunders, D. and Minton, J., 2003. Negotiation (4th ed.). Boston: McGraw-Hill/Irwin.

Markus, M., 1987. Toward a critical mass theory of interactive media - Universal access, interdependence and diffusion. Communication Research, 14(5), 491-511.

Mead, G., 1934. Mind, Self, and Society. Chicago: University of Chicago Press.

Morales, P., Urosa, B. and Blanco, A., 2003. Creating likert attitudes scales (1st edition ed.). Madrid: La Muralla.

Nunnally, J.C. and Bernstein, I.H., 1994. Psychometric Theory (3rd Ed ed.). New York: McGraw-Hill.

Raven, B., 1992. A power/interaction model of interpersonal influence: French and Raven thirty years later. Journal of Social Behavior and Personality, 7, 217-244.

Salancik, G. and Pfeffer, J., 1978. Social information-processing approach to job attitudes and task design. Administrative Science Quarterly, 23(2), 224-253.

Schmitz, J. and Fulk, J., 1991. Organizational colleagues, media richness, and electronic mail - a test of the social-influence model of technology use. Communication Research, 18(4), 487-523.

Short, J., Williams, E. and Christie, B., 1976. The social psychology of telecommunications. London: John Wiley \& Sons.

Te'eni, D., Sagie, A., Schwartz, D.G., Zaidman, N. and Amichai-Hamburger, Y., 2001. The process of organizational communication: A model and field study. IEEE Transactions on Professional Communication, 44(1), 6-20.

Trevino, L., Lengel, R. and Daft, R., 1987. Media symbolism, media richness, and media choice in organizations. Communication Research, 14(5), 553-574.

Vecchio, R. and Sussmann, M., 1991. Choice of influence tactics - individual and organizational determinants. Journal of Organizational Behavior, 12(1), 73-80.

Vishwanath, A., 2006. The effect of the number of opinion seekers and leaders on technology attitudes and choices. Human Communication Research, 32(3), 322350.

Williamson, J., Ranyard, R. and Cuthbert, L., 2000. A conversation-based process tracing method for use with naturalistic decisions: An evaluation study. British Journal of Psychology, 91, 203-221.

Yates, J. and Orlikowski, W., 1992. Genres of organizational communication - A structurational approach to studying communication and media. Academy of Management Review, 17(2), 299-326.

Yukl, G., 1989. Managerial leadership - a review of theory and research. Journal of Management, 15(2), 251-289.

Yukl, G. and Falbe, C., 1990. Influence tactics and objectives in upward, downward, and lateral influence attempts. Journal of Applied Psychology, 75(2), 132-140.

Yukl, G. and Tracey, J.B., 1992. Consequences of Influence Tactics used with Subordinates, Peers, and the Boss. Journal of Applied Psychology, 77(4), 525535.

Yukl, G., Chavez, C. and Seiefert, C., 2005. Assessing the construct validity and utility of two new influence tactics. Journal of Organizational Behavior, 26(6), 705-725. 
Yukl, G., Seiefert, C. and Chavez, C., 2008. Validation of the extended Influence Behavior Questionnaire. The Leadership Quarterly, 19, 609-621. 